DOI 10.37882/2223-2982.2021.09.21

\title{
ФОРМИРОВАНИЕ МЕТАФОРИЧЕСКОЙ МОДЕЛИ В ПОЛИТИЧЕСКИХ ПРЕДВЫБОРНЫХ ДЕБАТАХ
}

\section{FORMATION OF A METAPHORIC MODEL IN POLITICAL PRE-ELECTION DEBATE}

V. Neiman

Summary: Election campaigns are aimed at attracting adherents to the polling stations and convincing those few voters who have not yet made a decision. Political speech plays a large role in these efforts across a variety of communication platforms, but messages that mobilize one kind of voter may be ineffective or even counterproductive to another. Over the past two decades, scholars from different research points of view have carefully studied the impact of the metaphorical frame on political persuasion. Metaphors are often used to represent political interests. Politicians use metaphors to characterize themselves, their opponents and their political agendas, and they use metaphorical language in political debate to guide the public towards a particular point of view.

Keywords: political linguistics, metaphor, metaphorical model, metaphorical framing, conceptual metaphor, persuasion, impact.

\author{
Нейман Валентина Николаевна \\ Ассистент, Ханты-Мансийская государственная \\ медицинская академия, г. Ханты-Мансийск \\ v-tiunova@list.ru
}

Аннотация: Избирательные кампании направлены на то, чтобы привлечь сторонников на избирательные участки и убедить тех немногих избирателей, которые еще не приняли решение. Политическая речь играет большую роль в этих усилиях на различных коммуникационных платформах, но сообщения, которые мобилизуют один вид сторонников, могут быть неэффективными или даже контрпродуктивными для другого. За последние два десятилетия ученые, придерживающиеся различных исследовательских точек зрения, тщательно изучали влияние метафорического фрейма на политическое убеждение. Метафоры часто используются для обозначения политических интересов. Политики используют метафоры для характеристики себя, своих оппонентов и своих политических программ, а также используют метафорический язык в политических дебатах, чтобы направить общественность к определенной точке зрения.

Ключевые слова: политическая лингвистика, метафора, метафорическая модель, метафорический фрейминг, концептуальная метафора, убеждение, воздействие.

боры, потому что это балаган. (П.Н. Грудинин, 28.02.2018);

Tohle není vlastně varieté, to je to jsou velmi důležité otázky života a smrti. - здесь совсем не варьете, это очень важные вопросы жизни и смерти (П. Фишер, 11.01.2018);

Я пишу все сама, а Вы ходите с носом клоунским перебивая кандидатов (К.А. Собчак, 28.02.2018);

A v té vnitřní debatě, která je zapotřebí, prezident může sehrát naprosto klíčovou roli. - А во внутренних дебатах, которые необходимы, президент может сыграть абсолютно ключевую роль (здесь и далее перевод автора статьи) (П. Фишер, 11.01.2018).

Метафора играет важную роль в нашем понимании и в формировании наших мыслей и идей. Более того, метафора имеет тенденцию ярко выражать и передавать чувства, эмоции и мысли. В политике метафора действует как сильный и важный инструмент для выражения политических проблем, передачи идей и идеологий, чтобы слушатель / читатель соглашался с говорящим, а также для навязывания людям определенных моральных или этических ценностей.

Для современной лингвистики характерны представления о концептуальной метафоре как способе познания действительности. В данной области важными являются теоретические исследования Дж. Лакоффа, А. Мусолффа, Н.Д. Арутюновой, А.Н. Баранова, Ю.Н. Карауловой, Е.С. Кубряковой и других ученых.
Примеры похожих метафор:

Я не собираюсь в этом участвовать больше, потому что именно вы делаете так чтобы люди не пришли на вы- 
Н. Фэйрклаф утверждает, что политический язык - это «кровь или материнское молоко политиков, потому что общение - это важнейшая деятельность, которая связывает вместе различные части общества и позволяет им функционировать как единое целое» $[5,85]$. Согласно Блэку, метафора в политике является «принципиально убедительным дискурсивным актом» [3, 13]. Уилсон, с другой стороны, утверждает, что политики могут манипулировать метафорами, чтобы выявить абсурдные образы, которые можно использовать против своих политических соперников. Другими словами, метафора позволяет политикам представить себя в позитивном свете, унизить своих соперников, оправдать свои действия и отстаивать определенные политические интересы $[17,43]$.

Согласно Лакоффу и Джонсону, метафора - это понимание или переживание одной вещи или одной концепции в терминах другой, где есть некоторое сходство [8, 55]. По их словам, существует три типа метафор, которые используются для более четкой концептуализации менее четких деталей в терминах. Эти типы: ориентационная метафора, онтологическая метафора и структурная метафора. Настоящее исследование использует теорию метафор Лакоффа и Джонсона $[8,59]$.

Ориентационные метафоры «организуют целую систему понятий по отношению к другим» - и они «придают концепции пространственную ориентацию» $[8,14]$. Пространственная ориентация метафор действует подобно нашему телу в физической среде. Считается, например, что физическое состояние человека в грустном состоянии понижается, в то время как когда кто-то счастлив, его рост прямой $[8,15]$. Эти метафоры обеспечивают пространственные отношения между человеческим субъектом и чем-то, что находится в мире.

Предлагаю всем людям, семьи которых живут ниже уровня бедности отменить подоходный налог (Г.А. Явлинский, 28.02.2018);

У нас каждый седьмой человек в России живет за чертой бедности (К.А. Собчак, 14.03.2018);

Cítím se na vrcholu svých fyzických sil a zároveň se cítím do té těžké služby povolán. - Я чувствую себя на пике своих физических сил и в то же время чувствую себя призванным на эту трудную службу (П. Фишер, 11.01.2018);

Prezidentská funkce je zvláštní v tom, že ten prezident přece jenom nastavuje určitou lat'ku a myslím, že musí začít sám u sebe. - Особенность президентского аппарата состоит в том, что президент устанавливает планку, и я думаю, что он должен начать с себя (М. Горачек, 11.01.2018).

С другой стороны, онтологические метафоры тот случай, когда рассматривается что-то конкретное, как если бы оно было чем-то абстрактным [8, 25]. Он основан на опыте работы с физическими объектами. Это считается одним из наиболее важных методов, используемых для понимания нашего опыта. Онтологические метафоры делятся на три типа: метафора контейнера, метафора сущности и метафора субстанции.

Метафора контейнера изображает идеи как имеющие внутреннее и внешнее и способные удерживать что-то еще $[8,29]$. Соавторы рассматривают людей как контейнеры с границами и ориентацией «внутрь-наружу». Эта ориентация применяется к физическим объектам, которые можно рассматривать как контейнеры, и к нефизическим объектам, таким как события, действия, действия и состояния.

Десятки миллионов га стоит пустыми (В.В. Жириновский, 28.02.2018);

My jsme otevřená ekonomika. - Мы являемся открытой экономикой (П. Фишер, 11.01.2018).

Метафора сущности и субстанции обоснована опытом обращения с материальными объектами и способствует восприятию событий, эмоций, идей и т.п. как материальных сущностей и субстанций.

Налог НДС тормозит развитие страны (В.В. Жириновский 28.02.2018);

За это время развивающиеся страны, с кем мы в основном конкурируем, выросли на 55\% (Б.Ю. Титов, 28.02.2018);

Protože naše demokracie stojí na třech pilírích, které se vzájemně vyvažují moci exekutivní výkonné a právě soudní. - Потому что наша демократия основана на трех столпах, которые уравновешивают исполнительную и судебную власть (М. Горачек, 11.01.2018);

Vidíme v globalizovaném světě, že zde vyrůstají velké velmoci, které se začínají chovat poměrně agresivně jako je Čína. - В глобализованном мире мы видим, что здесь растут крупные державы, которые начинают вести себя довольно агрессивно, как Китай (М. Гилшер 11.01.2018).

Напротив, структурная метафора используется для того, чтобы люди понимали и воспринимали одно с точки зрения другого $[8,5]$, например, «спор как война», в этом примере «спор» концептуализируется так, как будто это война и что одна из сторон в споре должна его выиграть. В следующий примерах можно также выделить такие сферы «государство как живой организм» и «политика как театр».

Мы должны, во-первых, перестать быть страной, которая сидит на нефтяной игле (К.А. Собчак, 28.02.2018);

Это ложный путь, это не оппозиционеры, это просто театральные актеры, которые играют свою очень непримечательную роль и некрасивую роль на этих выборах (К.А. Собчак, 14.03.2018);

Chci společnost, která se pře, pře se plodně, ale nikdo není z toho sporu vylučován. - Я хочу общество, которое борется, борется плодотворно, но никто из этого спора не исключается (М. Горачек, 11.01.2018); 
Prezident, český prezident v tomto měl hrát důležitou úlohu, ale měl by také spolupracovat společně s vládou. Президент, чешский президент должен был сыграть в этом важную роль, но он также должен работать вместе с правительством (М. Гилшер, 11.01.2018).

Важная дискуссия в исследовании метафор связана с отношениями между лингвистическими и концептуальными метафорами. Лингвистические метафоры обычно определяются как перекрестные сопоставления значений слов. Концептуальные метафоры определяются как мысленные кластеры кросс-доменных отображений [8]. Метафора относится не к сфере слов, а к сфере мысли и действия. Наша концептуальная система построена на основе образов и носит метафорический характер. Поскольку значительная часть социальной реальности интерпретируется в метафорических терминах, а наше представление о материальном мире частично также является метафорическим, метафора играет очень важную роль в установлении того, что для нас реально $[2,244]$.

Лингвистические метафоры строятся на определенных шаблонах: концептуальных метафорах или метафорических моделях, действующих на бессознательном уровне. Суть концептуальных метафор не в словах, а в самом понимании предметов. Например, метафорические выражения «высокие / низкие чувства» основаны на концептуальной модели «вверх» - хорошо, вниз - плохо. Подобные метафоры носят системный характер и включают в себя целую сеть взаимосвязанных конструкций.

Рассмотрим следующие примеры концептуальной метафоры:

Мы впервые подошли к главной цели (В.В. Жириновский 14.03.2018);

К сожалению, наше правительство не имеет четкого плана: куда мы идем, как мы развиваем нашу экономику (Б.Ю. Титов, 14.03.2018);

Нам нужно идти по тому пути, который принесет уважение (Г.А. Явлинский, 14.03.2018)

В основе семантики выражения «идти по пути» находится метафора «жизнь - это путь». Область цели в данном случае «жизнь» уподобляется области источника - «путь», «путешествие».

Концептуальные метафоры (например, «жизнь - это путь»), облегчают понимание абстрактных концепций, связывая их, например, с концепциями, которые более знакомы и значимы для человека. Следовательно, теория концептуальных метафор утверждает, что использование метафор является одной из наиболее фундаментальных форм рассуждения [8]. Учитывая эту гипотезу о том, что люди рассуждают метафорически, метафоры в языке (например, «прошел путь», «препятствие», «попутчик») считаются последующими проявлениями этих метафор в мышлении [16, 42].

Что касается области дискурса, мы сосредотачиваемся на политическом дискурсе, потому что эта область была широко признана как метафорическая по своей сути [10]. Основная цель настоящего исследования - указать на использование политиками метафор в политических выступлениях, раскрыть различные типы используемых метафор и то, как политики пытаются донести свои послания до аудитории с помощью метафор.

Исследование процесса метафоризации как способа мышления и инструмента рассуждения в политической коммуникации основано на понимании метафоры как средства описания политической картины мира.

Одна из причин, по которой теория концептуальных метафор предполагает, что использование метафор является одной из наиболее фундаментальных форм рассуждений, заключается в том, что различные концептуальные метафоры способствуют различным соображениям по любой обсуждаемой теме [8]. В литературе это часто описывается как «обрамляющая сила» метафор $[15,627]$. Например, концептуальная метафора экономических проблем «погода» - это обычный способ думать и говорить об экономике (например, «экономический шторм», «денежный дождь» и «кредитная засуха»). Следуя теории концептуальной метафоры, ученые предположили бы, что эта концептуальная метафора должна заставить людей поверить в то, что экономические проблемы всегда находятся вне нашего контроля $[16,44]$. Так, например, описание явлений с характеристикой стихии наделяет их способность появляться внезапно и приносит бедствия.

Naše armáda by měla zasahovat a podílet se na těch misích, které taky mimo jiné přispívají k tomu, aby k nám neplynuly uprchlíci. - Наша армия должна вмешаться и принять участие в тех миссиях, которые, помимо прочего, также помогают предотвратить поток беженцев к нам (М. Гилшер, 11.01.2018);

Dokud ne stabilizujeme ty území, tak můžeme mluvit o nějakém volcano ne? - Пока мы не стабилизируем эти территории, мы можем говорить о каком-то вулкане, не так ли? (П. Фишер, 11.01.2018).

Метафорическая модель включает в себя более обширные значения, которые можно анализировать на разных уровнях языка. Такие модели можно рассматривать как своеобразные схемы, с помощью которых человек мыслит и действует. По мнению А.П. Чудинова «метафорическое моделирование - это отражающее национальное, социальное и личностное самосознание средство постижения, рубрикации, представления и оценки какого-то фрагмента действительности при помощи сценариев, фреймов и слотов, относящихся к совершенно иной понятийной области» $[20,48]$. Мета- 
форическая модель представляет собой схему «А - это Б» $[20,48]$ где A -это «сфера-источник», характерный выразительностью и эмоциональностью, а Б - «сферамишень», имеющий стандартное и всем понятное значение. Образные номинации помогают структурировать малоизвестную сферу-мишень благодаря хорошо знакомым элементам сферы-источника.

Что касается политического дискурса, теория морального суждения (moral reasoning) [10] предполагает, что разные политические идеологии строятся на основе разных метафорических моделей. Согласно этой теории, и консерваторы, и либералы образно рассуждают о нации как семье, правительстве как родителе и гражданах как детях. Однако консерваторы обычно следуют модели строгого отца, тогда как либералы следуют модели заботливого родителя [10].

Предыдущее исследование теории морального суждения [10] выявило метафорические модели строгого отца и заботливого родителя с использованием двух разных уровней анализа. В то время как некоторые ученые сосредотачиваются на значении слов на уровне слов, другие ученые сосредотачиваются на уровне понятий [14]. Ученые, специализирующиеся на словах [1], идентифицируют две модели, ища метафорические выражения, принадлежащие одной из двух метафорических моделей. Обычно они сначала составляют список лексических элементов, таких как существительные, глаголы и прилагательные, связанных с исходными областями двух моделей, таких как «сила» (строгий отец) и «поддержка» или «процветание» (заботливый родитель). Затем они определяют, действительно ли эти лексические элементы используются метафорически в моральных утверждениях в политическом дискурсе. Это означает, что выводы о наличии в политическом дискурсе рассуждений строгого отца и воспитывающего родителя делаются исключительно на основе наличия метафорических выражений, соответствующих этим метафорическим моделям.

Напротив, исследования, сосредоточенные на концепциях, идентифицируют две метафоры, ища ссылки на общие идеи, связанные с двумя метафорами, такими как самодисциплина (строгий отец; «усердно работать», «быть независимым») или доброта (заботливый родитель; «работать вместе», «помогать друг другу»). Сначала они разрабатывают таксономию или список примеров морального выражения для каждой метафоры на основе описания двух метафорических моделей Лакоффом [10]. Затем они классифицируют все моральные утверждения в политическом дискурсе, который они исследуют, в соответствии с этой систематикой. Это означает, что наличие аргументации «строгий отец» или «заботливый родитель» в политическом дискурсе определяется на основе наличия выражений, которые в более общем плане отражают семантические отношения, лежащие в основе метафорических моделей. Эти выражения могут быть метафорическими, но это не обязательно $[4,45]$.

Хотя оба подхода измеряют одно и то же явление - метафорическое мышление, выбор одного из двух уровней анализа, слова или понятия, может привести к разным результатам при применении к одним и тем же данным.

Исследования по обрамлению метафорических слов используют фреймы, которые состоят из метафорических выражений, в которых одна область описывается посредством другой области. Примером может служить исследование Калмо [7], который проанализировал влияние использования боевых слов (например, «битва», «борьба», «атака») для представления политики как войны (вместо неметафорического описания) на поддержку за политическое насилие.

Ниже в таблицах 1 и 2 представлен результат анализа метафор в дискурсе кандидатов на пост президента России и Чехии в дискурсе предвыборных дебатов. Чаще всего кандидаты на пост президента России в дебатах используют онтологическую метафору, что может указывать на то, что восприятие явлений и действий связывают с материальными предметами и веществами. Возможно, это способствует лучшему понимаю позиции политика электоратом. Среди кандидатов на пост президента Чехии преобладает структурная метафора, что указывает на стремление перенести свои идеи в уже существующие понятные и общедоступные понятийные сферы. Наиболее часто используемая сфера-источник в дискурсе политиков двух стран «борьба/война», но также часто можно встретить такие сферы как «театр» и «стихия».

Таблица 1

\begin{tabular}{|c|c|c|c|}
\multirow{2}{*}{$\begin{array}{c}\text { Кандидат на } \\
\text { пост президента } \\
\text { РФ }\end{array}$} & \multicolumn{3}{|c|}{ Виды использованных метафор } \\
\cline { 2 - 4 } & Ориентационная & Онтологическая & Структурная \\
\hline П.Н.Грудинин & $0 \%$ & $\mathbf{7 7 \%}$ & $23 \%$ \\
\hline $\begin{array}{c}\text { В.В. } \\
\text { Жириновский }\end{array}$ & $4,5 \%$ & $\mathbf{6 8 \%}$ & $27 \%$ \\
\hline К.А. Собчак & $11,5 \%$ & $23 \%$ & $\mathbf{6 5 , 5 \%}$ \\
\hline Б.Ю. Титов & $4,5 \%$ & $\mathbf{8 6 , 5 \%}$ & $9 \%$ \\
\hline Г.А.ЯВлинский & $20 \%$ & $\mathbf{4 0 \%}$ & $\mathbf{4 0 \%}$ \\
\hline
\end{tabular}

Таблица 2

\begin{tabular}{|c|c|c|c|}
\hline \multirow{2}{*}{$\begin{array}{c}\text { Кандидат на } \\
\text { пост президента } \\
\text { чр }\end{array}$} & \multicolumn{3}{|c|}{ Виды использованных метафор } \\
\hline & Ориентационная & Онтологическая & Структурная \\
\hline М. Гилшер & $12,5 \%$ & $37,5 \%$ & $50 \%$ \\
\hline М. Горачек & $31,5 \%$ & $52,6 \%$ & $15,7 \%$ \\
\hline Й. Дрогаш & $0 \%$ & $33,3 \%$ & $66,6 \%$ \\
\hline М. Тополанек & $16,6 \%$ & $41,6 \%$ & $41,6 \%$ \\
\hline П. Фишер & $33,3 \%$ & $33,3 \%$ & $33,3 \%$ \\
\hline
\end{tabular}


Несмотря на разницу в количестве видов метафор, которые использовали кандидаты двух стран, можно заявиться, что выбор метафоры во многом схож как по речевым ситуациям, так и по содержанию.

Анализ демонстрирует, что изучение метафориче- ских моделей необходимо для продвижения исследования метафор, потому как результаты показывают, что метафоры могут влиять на мнение людей посредством слов и понятий. Соответственно, исследования подтверждают, что использование метафор является одним из самых фундаментальных форм мышления.

\section{ЛИТЕРАТУРА}

1. Ahrens, K. Examining conceptual worldviews though lexical frequency patterns: a case study of U.S. presidential speeches. In S. Handl \& H. Schmid (Eds.), Windows to the mind: metaphor, metonymy and conceptual blending. Berlin: De Gruyter Mouton, 2011; 167-184.

2. Akmedov B.Y., Hamidova I.O. The role of metaphor in the formation of a linguistic picture of the world. International journal of progressive science and technologies. 2021; Vol. 25, №. 2: 242-246.

3. Black, J. Corpus Approaches to critical Metaphor Analysis, Basingstoke: Palgrave Macmillan, 2004.

4. Brugman B.C., Burgers C. Metaphorical framing in political discourse through words vs. concepts: a meta-analysis. Language and cognition. 2019; №. 11: 41-65.

5. Fairclough, N. New Labour, New Language. London: Routledge, 2000

6. Jasim S.A. An analysis of metaphor in selected political speeches. Journal university of Kerbala. 2018; vol. 16, №. 16: 16-25.

7. Kalmoe, N.P. Fueling the fire: violent metaphors, trait aggression, and support for political violence. Political Communication. $2014 ; 31$ (4), 545-563.

8. Lakoff, G. and M. Johnson. Metaphors we live by. Chicago: University of Chicago Press. 1980.

9. Lakoff, G. Metaphor and war: The metaphor system used to justify the war in the Gulf. In M. Pütz (ed). Thirty years of linguistic evolution. Amsterdam and Philadelphia: John Benjamins. 1992; 463-481.

10. Lakoff, G. Moral politics: how liberals and conservatives think (2nd ed.). Chicago: Chicago University Press, 2002

11. Malan S. Conceptual metaphors in South African political speeches (1994-2001). Stellenbosch papers in linguistics. 2008; vol. 38: 73-106.

12. Musolff, A Political Metaphor Analysis / A.Musolff - London: Bloomsberry Academic, 2016, - $209 \mathrm{p}$.

13. Osborn M.M., Ehninger D. The metaphor in public address. Speech monographs. 2009; 29:3, 223-234.

14. Renardel de Lavalette K.Y.R., Steen G.J., Burgers C. (in press). How to identify moral language in presidential speeches: a comparison between a socialpsychological and a metaphorical-words framing to corpus analysis. Corpus Linguistics and Linguistic Theory. doi:10.1515/cllt-2016-0007

15. Semino, E., Demjén, Z., \& Demmen, J. (2018). An integrated approach to metaphor and framing in cognition, discourse, and practice, with an application to metaphors for cancer. Applied Linguistics. 2018; 39 (5), 625-645.

16. Tameryan T.Y., Zheltukhina M.R., Slyshkin G.G., Abakumova 0.B., Volskaya N.N., Nikolaeva A.V. Metaphor in political media discourse: Mental political leader portrait. Online journal of communication and media nechnologies. 2018; 8 (4), 377-384.

17. Wilson, J. Politically Speaking. Oxford: Basil Blackwell, 1990.

18. Баранов, А.Н., Караулов Ю.Н. Словарь русских политических метафор. Москва: 1994.

19. Чудинов А.П. Политическая лингвистика. - М.: Флинта, 2006.

20. Чудинов А.П. Россия в метафорическом зеркале: когнитивное исследование политической метафоры. - Екатеринбург, 2001.

(c) Нейман Валентина Николаевна (v-tiunova@list.ru). 